\title{
Análise da Qualidade em Objetos de Aprendizagem: reflexão sobre aspectos pedagógicos
}

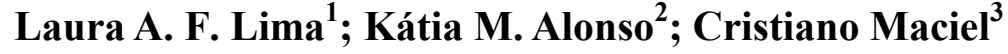 \\ ${ }^{1}$ Universidade Federal de Mato Grosso, laura.aflima@gmail.com; ${ }^{2}$ Universidade Federal de Mato Grosso, \\ katia@nead.ufmt.br; ${ }^{3}$ Universidade Federal de Mato Grosso, crismac@gmail.com
}

\begin{abstract}
This work aims to contribute to the deepening of the study of standards of quality assessment of learning objects, by observing pedagogical aspects and criteria that must be present in order to share knowledge, experiences and reflections on the use of Learning Objects. Whereas the real contribution of Learning Objects in the process of teaching and student learning, has caused unease in terms of quality in relation to pedagogical aspects present in its use, this study proposes the understanding and reflection of the pedagogical aspects outlined in instruments assessment, as the instruments of CCEAD PUC-Rio, NUTED, LORI HEODAR and to detect the presence and absence of these aspects and propose a new set of pedagogical aspects.
\end{abstract}

Resumo. Este trabalho tem o objetivo de contribuir para o aprofundamento do estudo de padrões de avaliação da qualidade de Objetos de Aprendizagem, mediante a observação de aspectos e critérios pedagógicos que devem estar presentes no propósito de partilhar conhecimento, experiências e reflexões no uso de Objetos de Aprendizagem. Considerando que a real contribuição dos Objetos de Aprendizagem, no processo de ensino-aprendizagem do estudante, tem provocado inquietação em termos de qualidade em relação a aspectos pedagógicos presentes em seu uso, este estudo propõe a compreensão e reflexão dos aspectos pedagógicos, delineados em instrumentos de avaliação, como os instrumentos da CCEAD PUC-Rio, NUTED, LORI e HEODAR, para detectar a presença e ausência destes aspectos e propor um novo conjunto de aspectos pedagógicos.

\section{Introdução}

A investigação do tema apoiou-se em estudo bibliográfico, objetivando compreender aspectos pedagógicos em Objetos de Aprendizagem (OAs) e o modo de identificá-los quando presente no uso de OAs disponíveis em repositórios virtuais.

Para este estudo, consideram-se aspectos pedagógicos grupos de elementos que podem estar presentes em OAs para auxiliar a aprendizagem e o ensino, e que, portanto, têm o intuito de facilitar o alcance das expectativas dos alunos e professores, a fim de apoiar a produção de conhecimento nos processos educativos. Para tanto, são aspectos pedagógicos em OAs aqueles que podem ser identificados com o uso do OA, tais como clareza do conteúdo, carga informacional adequada, identificação de pré-requisitos, atividades de reflexão, feedback claro e conciso ao término das atividades realizadas, entre outros.

\section{Metodologia}

Para tanto, foram selecionados quatro instrumentos de avaliação muito utilizados em repositórios virtuais públicos; dois deles são nacionais, da CCEAD PUC-RIO e NUTED; e os outros instrumentos são de uso internacional, LORI (Canadá e Estados Unidos) e HEODAR (Espanha). Os instrumentos foram analisados e, posteriormente, a 
discussão foi ampliada a outras bibliografias, em destaque Kemczinski et al. (2011). Todos os instrumentos foram selecionados com base em pesquisas na Web que possibilitaram identificar em repositórios nacionais e internacionais, a credibilidade do uso de CCEAD PUC-RIO, NUTED, LORI e HEODAR.

Desse modo, o objetivo deste estudo é investigar aspectos pedagógicos contemplados em OAs, identificando a presença destes como suporte aos processos educativos. Para tanto, envolve uma pesquisa exploratória baseada na abordagem qualitativa, tendo em seu percurso a utilização de alguns dados e interpretações de aspectos pedagógicos já pesquisados em instrumentos de avaliação de OAs, que são agregados e analisados de tal forma a tornar possível uma nova interpretação dos aspectos, reunidos em conjunto para serem identificados no uso de OAs.

A partir desta nova perspectiva, foi possível obter como resultado a elaboração de um conjunto de aspectos pedagógicos que possibilitam a geração de indicadores para apoiar o uso de OAs em processos educativos.

\section{Os instrumentos de avaliação}

Os instrumentos de avaliação auxiliam professores e alunos a selecionar os OAs (OAs) em função de sua qualidade e relevância, de acordo com o contexto em que estão inseridos (OTAMENDI et al., 2003?). Na prática, são questionários (desenvolvidos em softwares ou em folhas de papel) a serem preenchidos por um especialista em OA, professor ou aluno (cada qual direcionado a um nível dentre esses três, normalmente) que, após utilização do OA registrarão suas experiências e/ou opiniões a respeito das possibilidades pedagógicas e técnicas encontradas no uso do OA.

LORI é um instrumento que permite avaliar os OAs em função de nove variáveis, aqui limitadas, devido ao escopo do trabalho a apresentar e para analisar as variáveis relacionadas a elementos pedagógicos dos OAs. Nesse instrumento, é possível identificar cinco grupos de aspectos pedagógicos: qualidade do conteúdo; adequação dos objetivos de aprendizagem; Feedback e adaptabilidade; motivação e reusabilidade (quadro 1).

Quadro 1 - Elementos pedagógicos do instrumento LORI.

\begin{tabular}{|c|c|c|}
\hline 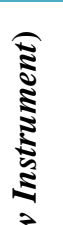 & 1 Qualidade do conteúdo & $\begin{array}{l}\text { - } \quad \text { apresentação equilibrada de ideias; } \\
\text { - } \quad \text { veracidade e precisão na apresentação do conteúdo; } \\
\text { - o conteúdo não apresenta omissões ou preconceito; } \\
\text { - os conteúdos reforçam pontos-chaves e ideias significativas. }\end{array}$ \\
\hline 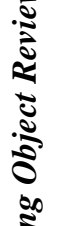 & $\begin{array}{l}2 \text { Adequação dos objetivos } \\
\text { de aprendizagem }\end{array}$ & $\begin{array}{l}\text { - } \quad \text { os objetivos de aprendizagem são claros; } \\
\text { - há relação entre os conteúdos, atividades e avaliações; } \\
\text { - } \quad \text { os objetivos são adequados ao perfil dos alunos; } \\
\text { - Há coerência entre os objetivos, atividades, avaliação e perfil } \\
\text { do aluno. }\end{array}$ \\
\hline 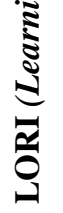 & $\begin{array}{l}3 \text { Feedback e } \\
\text { adaptabilidade }\end{array}$ & $\begin{array}{l}\text { - o Feedback garante a qualidade na compreensão da correção } \\
\text { das respostas do aluno; } \\
\text { mantém-se um registro das respostas ou estilo de } \\
\text { aprendizagem do aluno de maneira a adaptar as futuras } \\
\text { apresentações do conteúdo. }\end{array}$ \\
\hline
\end{tabular}




\begin{tabular}{|l|l|l|}
\hline 4 Motivação & $\begin{array}{l}\text { - o conteúdo é relevante na vida dos alunos; } \\
\text { - as atividades não são muito fáceis e nem muito difíceis; } \\
\text { - o OA varia em tom, há sinais de humor ou novidade na } \\
\text { apresentação dos conteúdos; }\end{array}$ \\
& $\begin{array}{l}\text { - a interação do aluno com o OA tem consequências } \\
\text { interessantes. }\end{array}$ \\
\hline 5 Reusabilidade & $\begin{array}{l}\text { pode ser integrado a um novo escopo pedagógico ou objetivo } \\
\text { de aprendizagem; } \\
\text { pode ser utilizado para distintos tipos de alunos adaptando o } \\
\text { conteúdo ou adicionando algum conteúdo como glossários, } \\
\text { sumários ou conceitos prévios. }\end{array}$ \\
\hline
\end{tabular}

1. Qualidade do conteúdo: remete à veracidade, precisão e apresentação equilibrada de ideias (OTAMENDI et al., 2003?). Nesse elemento é verificado o nível adequado de detalhe do conteúdo e se este não apresenta erros, inconsistências ou omissões que possam prejudicar o aprendizado do aluno. Também é avaliado neste item se os conteúdos são baseados em evidências ou argumentos lógicos que enfatizam pontos-chaves e ideias significantes. Ainda neste item são avaliadas as diferenças culturais ou relacionadas a grupos étnicos, representados de forma equilibrada nos conteúdos postados (OTAMENDI et al., 2003?).

2. Adequação dos objetivos de aprendizagem: remete à coerência entre os objetivos, atividades, avaliação e perfil do aluno (OTAMENDI et al., 2003?). A referência é feita aos objetivos de aprendizagem dentro do conteúdo, os quais podem estar disponíveis tanto no arquivo de metadados (dados sobre o OA, tais como autor, nível de dificuldade, conteúdo) do OA, com o propósito de serem apropriados pelos estudantes para os quais foram desenvolvidos, quanto nas atividades propostas, a fim e verificar seu conteúdo e tipos de avaliação. O OA em si pode auxiliar os alunos a atingirem os objetivos de aprendizagem (OTAMENDI et al., 2003?).

3. Feedback e adaptabilidade: remete à avaliação de conteúdo, que pondera se este é adequado, ou se o Feedback é direcionado de acordo com a resposta de cada aluno e o respectivo estilo de aprendizagem (OTAMENDI et al., 2003?).

4. Motivação: remete à capacidade de motivar e gerar interesse em um determinado grupo de alunos (OTAMENDI et al., 2003?). Do ponto de vista do aproveitamento do OA, é muito provável que o aluno mostre maior interesse no tema depois de tê-lo usado. Para tanto, é observado se o OA oferece simulações baseadas em atualidades, multimídia, interatividade, drama, humor e/ou desafios através de jogos que estimulam o interesse dos alunos (OTAMENDI et al., 2003?).

5. Reusabilidade: É a possibilidade de utilizar o OA em diferentes contextos pedagógicos e para alunos com diferentes estilos de aprendizagem e experiências de formação (OTAMENDI et al., 2003?). O OA oferece diferentes meios de abordagem para explicar o conceito de que trata, ou seja, oferece flexibilidade para incorporar componentes em múltiplas aplicações e contextos; assim, é possível de ser adaptado a um escopo de aprendizagem já em uso.

O instrumento de avaliação denominado HEODAR também foi concebido com o objetivo de avaliar as variáveis pedagógicas e técnicas dos OAs, uma vez que esse instrumento traz mais variáveis a serem avaliadas do que o LORI (MORALES MORGADO et al., 2007). Além disso, HEODAR é um instrumento integrado à plataforma Moodle, que se refere à avaliação de um OA, salvo no formato SCORM 
(IEEE LOM, 2002). Veja na Figura 7 que demonstra os aspectos pedagógicos identificados nesse instrumento.

O HEODAR possibilita avaliar aspectos pedagógicos relacionados com o educando (significado psicológico) e o currículo (significado lógico), inseridos em um OA concebido, conforme o padrão IEEE LOM, que requer metadados e um nível de interação adequado.

Quadro 4 - Aspectos pedagógicos identificados em HEODAR.

\begin{tabular}{|c|c|c|}
\hline \multirow{4}{*}{$\begin{array}{l}\text { Categoria } \\
\text { Psicopedagógica }\end{array}$} & $\begin{array}{l}\text { Aspectos gerais da } \\
\text { categoria }\end{array}$ & $\begin{array}{l}\text { - Apresentação atrativa e original: Chamar a atenção dos alunos } \\
\text { - } \quad \text { Informação relevante para a compreensão dos conteúdos; } \\
\text { - } \quad \text { Participação do aluno: está clara a participação do aluno no } \\
\text { decorrer do programa. }\end{array}$ \\
\hline & $\begin{array}{l}\text { Desempenho } \\
\text { profissional }\end{array}$ & $\begin{array}{l}\text { - Adequação às competências profissionais: alinhar a utilidade } \\
\text { dos conteúdos e atividades com as necessidades e desempenho } \\
\text { profissional dos alunos. }\end{array}$ \\
\hline & $\begin{array}{l}\text { Nível de } \\
\text { dificuldade } \\
\text { adequado às } \\
\text { características dos } \\
\text { alunos }\end{array}$ & $\begin{array}{l}\text { - Profundidade pertinente: profundidade adequada segundo } \\
\text { conhecimentos prévios e o nível de complexidade que o aluno é } \\
\text { capaz de compreender. } \\
\text { - Nível de linguagem: Linguagem utilizada adequada (termos } \\
\text { técnicos, etc.) aos conhecimentos prévios dos alunos. }\end{array}$ \\
\hline & Interatividade & $\begin{array}{l}\text { - Nível de interatividade: promove atividades abertas, diversas } \\
\text { maneiras de resolver problemas; proporciona realimentação e } \\
\text { correção de erros. }\end{array}$ \\
\hline \multirow{3}{*}{$\begin{array}{l}\text { Categoria } \\
\text { Didático- } \\
\text { curricular }\end{array}$} & Contexto & $\begin{array}{l}\text { - Nível de formação adequado à situação educacional: por } \\
\text { exemplo, } 2^{\mathrm{a}} \text { série da educação básica. } \\
\text { - Descrição da Unidade (lição): apresenta introdução ou resumo } \\
\text { que explica de maneira clara a unidade. }\end{array}$ \\
\hline & Objetivos & $\begin{array}{l}\text { - Formulado corretamente: formulados, geralmente, com verbo } \\
\text { no infinitivo + conteúdo + circunstância. } \\
\text { - Factível: que pode ser alcançado. } \\
\text { - Esclarece o que se espera que seja aprendido: o aluno deve ser } \\
\text { consciente do que ele tem que aprender. } \\
\text { - Coerente com os objetivos gerais: os objetivos específicos } \\
\text { devem ajudar a cumprir os objetivos gerais. }\end{array}$ \\
\hline & $\begin{array}{l}\text { Tempo de } \\
\text { aprendizagem }\end{array}$ & $\begin{array}{l}\text { - É o tempo de duração estimado para o desenvolvimento da } \\
\text { unidade - adequado ao tempo disponibilizado ou determinado. }\end{array}$ \\
\hline
\end{tabular}

O instrumento da CCEAD PUC-RIO foi amplamente utilizado pelas várias instituições nacionais participantes do Condigital, edital $n^{\circ} 1 / 2007$ para a produção de conteúdos educacionais digitais multimídia, lançado pelo Ministério da Educação, por meio da Secretaria de Educação a Distância. Nesse instrumento, os OAs são avaliados por especialistas e por alunos através dos seguintes instrumentos para a Avaliação da

1

O Projeto Condigital tem como objetivo a produção de conteúdos educacionais multimídia em parceria com FNDE, MCT, SEED/MEC e ÁGORA. Disponível em: http://www.coopagora.com.br/projetocondigital-lingua-brasil/ 
Qualidade de OAs disponíveis no site do programa: "instrumento de avaliação para especialistas" e "instrumento de avaliação para alunos". Para esta pesquisa, foram analisados os elementos pedagógicos do "instrumento de avaliação para especialistas" da CCEAD/PUC-Rio, que abrange maior número de elementos pedagógicos para o aprofundamento do estudo. O Instrumento da CCEAD/PUC-Rio foi analisado em sua versão 5.0, que apresenta elementos técnicos e pedagógicos dos OAs vídeo, áudio e software.

Quadro 5 - Aspectos pedagógicos identificados no instrumento para a avaliação da qualidade de OAs CCEAD/PUC-Rio.

\begin{tabular}{|c|c|c|}
\hline $\begin{array}{c}\text { Aspectos gerais } \\
\text { software, vídeo/áudio }\end{array}$ & $\begin{array}{l}\text { Aspectos específicos } \\
\text { vídeo e áudio }\end{array}$ & $\begin{array}{c}\text { Aspectos específicos } \\
\text { Software }\end{array}$ \\
\hline $\begin{array}{l}\text { - ambiente educacional; } \\
\text { - pertinência ao } \\
\text { programa curricular; } \\
\text { didática: } \\
\text { - aspectos } \\
\text { motivacionais e } \\
\text { respeito às } \\
\text { individualidades; } \\
\text { - clareza dos } \\
\text { conteúdos; } \\
\text { - correção dos } \\
\text { conteúdos; } \\
\text { - adequação do } \\
\text { vocabulário de } \\
\text { acordo com o } \\
\text { público-alvo; } \\
\text { - carga } \\
\text { informacional. }\end{array}$ & 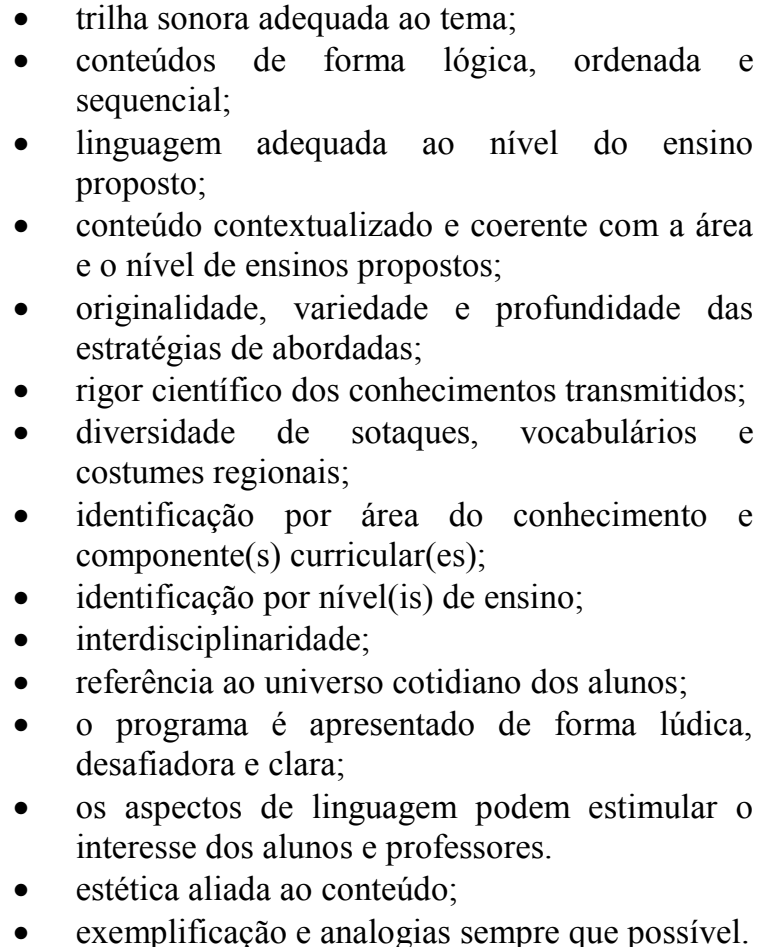 & $\begin{array}{l}\text { - } \quad \text { clareza das } \\
\text { - } \quad \text { facilidadermações; } \\
\text { localização das } \\
\text { informações; } \\
\text { - } \quad \text { pertinência; } \\
\text { - contextualização; } \\
\text { - correção de } \\
\text { - } \quad \text { fonteúdo; } \\
\text { acilidade de } \\
\text { interação; } \\
\text { - } \quad \text { referências; } \\
\text { - interatividade; } \\
\text { - } \quad \text { qualidade da } \\
\text { informação. }\end{array}$ \\
\hline
\end{tabular}

O Núcleo de Tecnologia Digital Aplicada à Educação (NUTED) está vinculado à Faculdade de Educação da Universidade Federal do Rio Grande do Sul (FACED/UFRGS), e faz parte do Centro Interdisciplinar de Novas Tecnologias na Educação (CINTED/UFRGS). O NUTED aborda várias linhas de pesquisa, tais como agentes pedagógicos, AVA e educação superior, arte \& design e $\mathrm{EaD}$, construção de AVA, construção de conhecimento em ambientes digitais, dentre outros. $\mathrm{O}$ instrumento de avaliação desse Núcleo de Tecnologia tem um padrão similar ao modelo usado no sistema MERLOT (Multimedia Educational Resource for Leaning and Online Teaching) ao referenciar os aspectos pedagógicos em três grupos principais que tratam da qualidade do conteúdo, sua usabilidade e didática.

O Quadro 6 é o resultado de um levantamento realizado para a análise de aspectos pedagógicos que devem estar presentes no uso de um OA.

Quadro 6 - Aspectos pedagógicos do instrumento do Núcleo de Tecnologia Digital Aplicada à Educação (NUTED). 


\begin{tabular}{|c|c|c|}
\hline 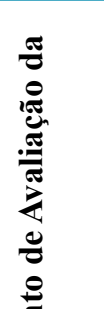 & Conteúdo & $\begin{array}{l}\text { - } \text { Claro e conciso; } \\
\text { - } \text { Altamente relevante; } \\
\text { - } \quad \text { Demonstra conceitos básicos; } \\
\text { - } \quad \text { Apresenta informaçoções precisas e atuais; } \\
\text { - Inclui quantidade apropriada de material; } \\
\text { - Apresenta alta qualidade (redação e edição). }\end{array}$ \\
\hline 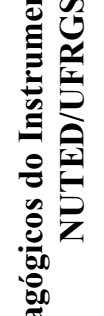 & Didática & 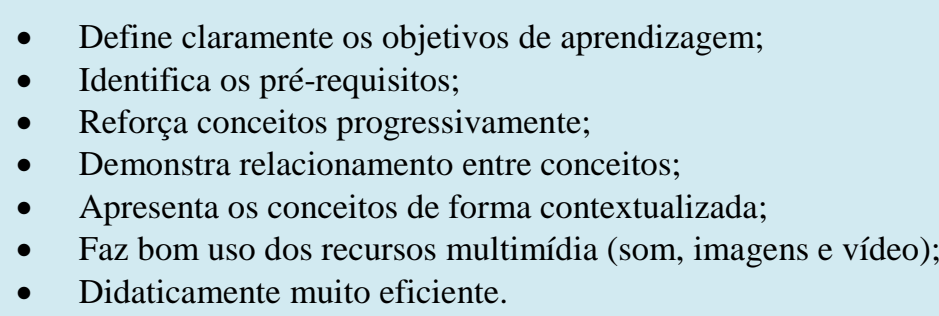 \\
\hline 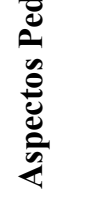 & "Usabilidade" & $\begin{array}{l}\text { - Tem instruções claras; } \\
\text { - É engajador / motivador; } \\
\text { - Visualmente atraente; } \\
\text { - É flexível e reutilizável; } \\
\text { - É interativo. }\end{array}$ \\
\hline
\end{tabular}

Além disso, vale ressaltar que os elementos pedagógicos identificados em estudo bibliográfico em Kemczinski et al. (2011), contribuíram significativamente na perspectiva de aspectos pedagógicos (principalmente os que advêm da interatividade) a serem avaliados em OAs. Percebe-se que eles se aproximam de elementos identificados nos instrumentos de avaliação, mas não de maneira destacada como aspectos pedagógicos de autonomia Loiselle (2002), cooperação Ramos e Santos (2006) e cognição Ferraz e Belhot (2010), Tarouco (2003).

Em linhas gerais, a análise dos resultados de avaliações de aspectos pedagógicos, presentes em OAs, por meio de analise de instrumentos de avaliação e estudo bibliográfico em Kemczinski et al. (2011) possibilitaram um guia facilitador para a elaboração de uma nova proposta de aspectos pedagógicos que permeiam o uso de OAs. No quadro 7 são apresentadas as categorias dos aspectos pedagógicos que foram identificados nos instrumentos de avaliação.

Quadro 7 - Aspectos pedagógicos identificados nos instrumentos de avaliação e a partir da revisão bibliográfica.

\begin{tabular}{|c|c|c|c|}
\hline $\begin{array}{c}\text { Instrumentos de } \\
\text { Avaliação }\end{array}$ & & Categorias & Aspectos Pedagógicos \\
\hline $\begin{array}{l}\text { LORI } \\
\text { (Quadro 3) }\end{array}$ & $\begin{array}{l}3 \\
4 \\
5\end{array}$ & $\begin{array}{l}\text { Qualidade do conteúdo; } \\
\text { Adequação dos objetivos de } \\
\text { aprendizagem; } \\
\text { Feedback e adaptabilidade; } \\
\text { Motivação; } \\
\text { Reusabilidade; }\end{array}$ & $\begin{array}{l}\text { Neste instrumento, as cinco categorias, que } \\
\text { mais seriam aspectos pedagógicos gerais, } \\
\text { englobam aspectos pedagógicos mais } \\
\text { específicos. }\end{array}$ \\
\hline $\begin{array}{l}\text { HEODAR } \\
\text { (Quadro 4) }\end{array}$ & $\begin{array}{l}1 \\
2\end{array}$ & $\begin{array}{l}\text { Psicopedagógica; } \\
\text { Didático-curricular; }\end{array}$ & $\begin{array}{l}\text { Possui duas categorias. Cada uma apresenta } \\
\text { um aspecto pedagógico geral e seus } \\
\text { respectivos } \\
\text { específicos. }\end{array}$ \\
\hline
\end{tabular}




\begin{tabular}{|c|c|c|c|}
\hline $\begin{array}{l}\text { CCEAD/PUC-Rio } \\
\text { (Quadro 5) }\end{array}$ & 3 & $\begin{array}{l}\text { Aspectos gerais: Software, } \\
\text { vídeo ou áudio; } \\
\text { Aspectos específicos: Vídeo e } \\
\text { áudio; } \\
\text { Aspectos específicos: } \\
\text { Software. }\end{array}$ & $\begin{array}{l}\text { O instrumento divide os aspectos } \\
\text { pedagógicos do OA quanto à possibilidade } \\
\text { de sua aplicação em determinadas } \\
\text { tecnologias, tais como software, vídeo ou } \\
\text { áudio. } \\
\text { O instrumento possui três formulários. O } \\
\text { primeiro formulário refere-se a aspectos } \\
\text { gerais, comuns a todas as tecnologias } \\
\text { citadas e os dois últimos são direcionados a } \\
\text { vídeo/áudio e software, respectivamente. }\end{array}$ \\
\hline $\begin{array}{l}\text { NUTED/URGS } \\
\text { (Quadro 6) }\end{array}$ & $\begin{array}{l}1 \\
2 \\
3\end{array}$ & $\begin{array}{l}\text { Conteúdo; } \\
\text { Didática; } \\
\text { "Usabilidade" }\end{array}$ & $\begin{array}{l}\text { Possui três categorias pedagógicas, que, de } \\
\text { forma similar ao LORI, são aspectos } \\
\text { pedagógicos gerais que englobam aspectos } \\
\text { pedagógicos mais específicos. A } \\
\text { "Usabilidade" está entre aspas porque, nesse } \\
\text { caso, é pedagógico e não técnico, basta } \\
\text { conferir seus aspectos pedagógicos } \\
\text { específicos. }\end{array}$ \\
\hline
\end{tabular}

\section{Análise dos Resultados: Elaboração do Conjunto de Aspectos Pedagógicos em OAs}

Primeiramente, será apresentado o grupo da categoria " 1 . Categoria Psicopedagógica" que apresenta oito aspectos pedagógicos que, em conjunto, englobam averiguações importantes como: captar a atenção do educando; oferecer informações suficientes para o entendimento do conteúdo; explicar claramente qual é a participação do aluno no decorrer do uso do OA; relacionar os conteúdos com as necessidades cotidianas dos alunos e sua expectativa profissional; adequar todo o conteúdo de acordo com o nível de instrução, conhecimentos prévios e nível de complexidade necessário; adequar a linguagem ao nível de instrução dos educandos; e promover atividades diversas, tais como atividades abertas para reflexão e possibilidade de realimentar o OA após a correção dos erros. Para tanto, seguem as análises das características psicopedagógicas importantes para apoiar a aprendizagem.

Em seguida, a "2. Categoria Currículo", que possui sete aspectos pedagógicos (Quadro 10), foi elaborada e descrita para esclarecer se o OA é pertinente ao programa curricular, se o nível de formação do aluno está de acordo com os documentos de planejamento e apresentação do OA ("Guia do Professor" para o planejamento do uso do OA e/ou "Design Pedagógico" do OA) e se os objetivos são específicos, realistas, mensuráveis e alcançáveis para os alunos das séries para as quais ele foi criado. Além disso, tem-se que verificar a relação da complexidade e carga informacional com o tempo estimado para as atividades no OA.

A terceira categoria analisada possui doze aspectos pedagógicos que tratam com mais detalhes da análise do conteúdo do OA, denominada "3. Categoria Conteúdo" (Quadro 11). Possibilita identificar e analisar aspectos pedagógicos tais como pertinência do conteúdo à área e subárea a que ele se propõe, relevância dos assuntos, clareza e concisão, atualização das informações apresentadas, rigor científico, referências apresentadas, etc.

Além dos aspectos pedagógicos das categorias 1,2 e 3, é importante ressaltar que os aspectos didáticos no OA também precisam ser identificados para apoiar os processos educativos e, portanto, constam na "4. Categoria Didática” (Quadro 12), para analisar se os conteúdos são retomados progressivamente, se os pré-requisitos foram estabelecidos, se a definição dos objetos é cumprida com o uso do OA, se favorece a 
interdisciplinaridade e se todos os assuntos seguem uma ordem lógica, do geral para os conceitos mais específicos (como foi visto na seção 1.3 do capítulo I que trata do mapa conceitual), etc.

O último grupo de aspectos pedagógicos a serem apresentados conta com a presença de nove deles, é a "5. Categoria Feedback e adaptabilidade" (Quadro 13), importante para verificar se o OA adapta-se às mensagens instrutivas ou atividades baseadas nas necessidades específicas do aluno; se por meio do OA é possível construir, junto com o aluno, uma aprendizagem fundamentada em suas próprias respostas; enfim, se há possibilidade de promover atividades abertas, diversas maneiras de resolver problemas, proporcionar realimentação e correção de erros.

A partir dos aspectos pedagógicos identificados e conceituados para cada uma das cinco categorias pedagógicas, foi elaborada a estrutura que reúne todos esses elementos de modo a propor uma nova perspectiva de aspectos pedagógicos presentes em OAs.

Alguns aspectos pedagógicos identificados se fazem presentes em mais de um instrumento de avaliação (algumas vezes utilizando sinônimos ou termos semelhantes, outras vezes aparecem de forma idêntica no escopo dos instrumentos); há outros aspectos que só se fazem presentes em um único instrumento, porém todos aqueles presentes no Conjunto de Aspectos Pedagógicos, recém-criado para apoiar os processos educativos (Quadro 7), é o resultado da junção dos aspectos pedagógicos encontrados nos Quadros 3, 4, 5, e 6 dos instrumentos no capítulo I (LORI, HEODAR, as normas da CCEAD/PUC-Rio e da NUTED/UFRGS), de três aspectos pedagógicos com base em Kemczinski et al. (2011), e dos aspectos que foram definidos conforme necessidade identificada durante a análise.

Essa estrutura é apresentada a seguir (Quadro 8), com o foco em aspectos pedagógicos que auxiliam os processos educativos, em especial a aprendizagem do educando.

Quadro 8 - Conjunto de aspectos pedagógicos recém-criado para apoiar os processos educativos.

\begin{tabular}{|c|c|c|c|c|}
\hline \multicolumn{5}{|c|}{ Aspectos Pedagógicos em OAs } \\
\hline $\begin{array}{l}1 \text { Categoria } \\
\text { Psicopedagógica }\end{array}$ & $\begin{array}{l}2 \text { Categoria } \\
\text { Currículo }\end{array}$ & $\begin{array}{l}3 \text { Categoria } \\
\text { Conteúdo }\end{array}$ & $\begin{array}{l}4 \text { Categoria } \\
\text { Didática }\end{array}$ & $\begin{array}{l}5 \text { Categoria } \\
\text { Feedback e } \\
\text { adaptabilidade }\end{array}$ \\
\hline $\begin{array}{l}1.1 \text { motivação e níve } \\
\text { de atenção }\end{array}$ & 2.1 contexto & 3.1 claro e conciso & $\begin{array}{l}4.1 \text { define claramente } \\
\text { os objetivos de } \\
\text { aprendizagem }\end{array}$ & $\begin{array}{l}5.1 \text { faz bom uso de } \\
\text { animações e } \\
\text { simulações }\end{array}$ \\
\hline $\begin{array}{l}1.2 \text { desempenho } \\
\text { profissional }\end{array}$ & $\begin{array}{l}2.2 \text { identificação } \\
\text { por nível(is) de } \\
\text { ensino }\end{array}$ & $\begin{array}{l}3.2 \text { adequação do } \\
\text { vocabulário de } \\
\text { acordo com o } \\
\text { público-alvo }\end{array}$ & $\begin{array}{l}4.2 \text { é possível que os } \\
\text { objetivos pretendidos } \\
\text { sejam alcançados com o } \\
\text { uso do OA }\end{array}$ & $\begin{array}{l}5.2 \text { tem instruções } \\
\text { claras. Recorre à } \\
\text { exemplificação e } \\
\text { analogias sempre que } \\
\text { possível }\end{array}$ \\
\hline $\begin{array}{l}1.3 \text { nível de } \\
\text { dificuldade adequad } \\
\text { ao nível dos } \\
\text { estudantes }\end{array}$ & 2.3 objetivos & $\begin{array}{l}3.3 \text { altamente } \\
\text { relevantes }\end{array}$ & $\begin{array}{l}4.3 \text { identifica os pré- } \\
\text { requisitos }\end{array}$ & $\begin{array}{l}5.3 \text { feedback é } \\
\text { direcionado de } \\
\text { acordo com a } \\
\text { resposta de cada } \\
\text { aluno }\end{array}$ \\
\hline $\begin{array}{l}1.4 \text { autonomia e níve } \\
\text { de participação do }\end{array}$ & $\begin{array}{l}2.4 \text { tempos } \\
\text { disponibilizados } \\
\text { para a }\end{array}$ & $\begin{array}{l}3.4 \text { demonstra } \\
\text { conceitos básicos }\end{array}$ & $\begin{array}{l}4.4 \text { reforça conceitos } \\
\text { progressivamente }\end{array}$ & $\begin{array}{l}5.4 \text { direcionado ao } \\
\text { estilo de } \\
\text { aprendizagem }\end{array}$ \\
\hline
\end{tabular}




\begin{tabular}{|c|c|c|c|c|}
\hline aluno & aprendizagem & & & \\
\hline 1.5 Interatividade & $\begin{array}{l}2.5 \text { pertinência } \\
\text { ao programa } \\
\text { curricular }\end{array}$ & $\begin{array}{l}3.5 \text { descreve bem os } \\
\text { conceitos }\end{array}$ & $\begin{array}{l}4.5 \text { demonstra } \\
\text { relacionamento entre } \\
\text { conceitos }\end{array}$ & $\begin{array}{l}5.5 \text { construir, junto } \\
\text { com o aluno, uma } \\
\text { aprendizagem } \\
\text { fundamentada em } \\
\text { suas próprias } \\
\text { respostas }\end{array}$ \\
\hline 1.6 nível de cogniçã & $\begin{array}{l}2.6 \text { ambiente } \\
\text { educacional }\end{array}$ & $\begin{array}{l}3.6 \text { apresenta } \\
\text { informações atuais }\end{array}$ & $\begin{array}{l}4.6 \text { apresenta os } \\
\text { conceitos de forma } \\
\text { contextualizada }\end{array}$ & $\begin{array}{l}5.6 \text { é apresentado de } \\
\text { forma lúdica, } \\
\text { desafiadora e clara }\end{array}$ \\
\hline 1.7 criatividade & 2.7 reusabilidade & $\begin{array}{l}3.7 \text { carga } \\
\text { informacional } \\
\text { apropriada }\end{array}$ & $\begin{array}{l}4.7 \text { faz bom uso dos } \\
\text { recursos multimídia } \\
\text { (som, imagens e vídeo) }\end{array}$ & $\begin{array}{l}5.7 \text { correção de } \\
\text { conteúdo }\end{array}$ \\
\hline \multirow[t]{5}{*}{1.8 cooperação } & & $\begin{array}{l}3.8 \text { apresenta alta } \\
\text { qualidade (redação e } \\
\text { edição) }\end{array}$ & $\begin{array}{l}4.8 \text { respeito às } \\
\text { individualidades }\end{array}$ & $\begin{array}{l}5.8 \text { facilidade de } \\
\text { aprendizagem da } \\
\text { localização das } \\
\text { informações }\end{array}$ \\
\hline & & $\begin{array}{l}3.9 \text { pertinência e } \\
\text { identificação por } \\
\text { área e subárea de } \\
\text { conhecimento }\end{array}$ & $\begin{array}{l}4.9 \text { preocupa-se com a } \\
\text { estética aliada ao } \\
\text { conteúdo }\end{array}$ & \\
\hline & & $\begin{array}{l}3.10 \text { contempla a } \\
\text { diversidade de } \\
\text { sotaques, } \\
\text { vocabulários e } \\
\text { costumes regionais }\end{array}$ & $\begin{array}{l}4.10 \text { faz referência ao } \\
\text { universo cotidiano dos } \\
\text { alunos }\end{array}$ & \\
\hline & & $\begin{array}{l}3.11 \text { apresenta rigor } \\
\text { cientifico dos } \\
\text { conhecimentos } \\
\text { transmitidos }\end{array}$ & $\begin{array}{l}4.11 \text { favorece a } \\
\text { interdisciplinaridade }\end{array}$ & \\
\hline & & 3.12 referências & $\begin{array}{l}4.12 \text { aborda os } \\
\text { conteúdos de forma } \\
\text { lógica, ordenada e } \\
\text { sequencial }\end{array}$ & \\
\hline
\end{tabular}

\section{Algumas Considerações}

Como dito anteriormente, o Conjunto de Aspectos Pedagógicos, representados pelo Quadro 7, foi elaborado com o intuito de apresentar uma nova estrutura de aspectos pedagógicos, após identificação e compreensão destes em fontes confiáveis já referenciadas. Com isso, o Conjunto de Aspectos Pedagógicos (Quadro 7) proporciona uma nova categorização e interpretação desses aspectos numa estrutura que permite analisar suas potencialidades e limitações em relação ao objetivo de avaliar os aspectos pedagógicos de OAs. Essa verificação é realizada ao final da análise pretendida.

Enfim, o Conjunto de Aspectos Pedagógicos (Quadro 7), é a base de toda a análise de OAs realizada nesta pesquisa (e que será explanada no capítulo III); para tanto ele foi aplicado em todas as análises feitas nos OAs selecionados neste estudo. Vale ressaltar que o Conjunto de Aspectos Pedagógicos (Quadro 7), assim como os quadros 9, 10, 11, 12 e 13, demonstra os "aspectos pedagógicos em OAs" considerando 
que cada grupo é independente e não exclusivo, de forma que qualquer OA possa ser construído observando-se quais aspectos pedagógicos apoiam a aprendizagem. Por isso foi imprescindível a descrição das categorias e a compreensão de seus respectivos aspectos pedagógicos para se chegar ao Conjunto de Aspectos Pedagógicos, representados pelo Quadro 7. Desse modo, também foi possível facilitar a análise do percurso realizado quanto ao uso dos quatro OAs selecionados, pois, o que se pretende saber é se esses elementos podem ser identificados nos OAs que foram selecionados para esta pesquisa.

\section{Referências Bibliográficas}

FABRE, M. C. J. M.; TAROUCO, L. M. R.; TAMUSIUNAS, F. R. Reusabilidade de objetos educacionais. RENOTE - Revista Novas Tecnologias na Educação. Porto Alegre, v. 1, n. 1, 2003. Disponível em: $<$ http://www.cinted.ufrgs.br/renote/fev2003/artigos/marie reusabilidade.pdf $>$. Acesso em: 13 ago. 2008.

KEMCZINSKI, A. et al. Repositório de OAs para a área de computação e informática ROAI. In: SIMPÓSIO BRASILEIRO DE INFORMÁTICA NA EDUCAÇÃO - SBIE, 22., 2011, Aracajú. Anais... Aracajú: [s.n.], 2011. p. 234-243.

LOISELLE, J. A exploração da multimídia e da rede internet para favorecer a autonomia dos estudantes universitários na aprendizagem. In: ALAVA, Séraphin (Org.). Ciberespaço e formações abertas: rumo a novas práticas educacionais? Tradução de Fátima Murad. Porto Alegre: Artmed, 2002.

MORALES MORGADO, E. M. et al. Sistema de gestión de objetos de aprendizaje de calidad. In: SIMPOSIO PLURIDISCIPLINAR SOBRE OBJETOS Y DISEÑOS DE APRENDIZAJE APOYADOS EN LA TECNOLOGIA (SPDECE'06), 3., 2006, Oviedo, Espanha. Anais... Oviedo, Espanha: [s.n.], 2006. Disponível em:

$<$ http://www.sloopproject. eu/sloop/file.php/24/Documentos/od_06_Morales_etal.pdf >. Acesso em: 10 mar. 2012.

.; GÓMEZ AGUILAR, D. A.; GARCÍA PEÑALVO, F. J. HEODAR:

Herramienta para la Evaluación de Objetos Didácticos de Aprendizaje Reutilizables. In: SIMPOSIO INTERNACIONAL DE INFORMÁTICA EDUCATIVA (SIIE'08), 10., 2008, Salamanca, Espanha. Anais... Salamanca, Espanha: Ediciones Universidad de Salamanca, 2008. p. 181-186.

OTAMENDI, Ainhoa et al. Instrumento para la evaluación de objetos de aprendizaje (LORI_ESP): manual de usuario. Version 1.0. España: [s.n., 2003?]. 12 p. Spanish version of the Learning Object Review Instrument (LORI-ESP). Disponível em: <http://www.unizar.

es/CBSantander/images/2010/OER/Instrumento\%20para $\% 201 \mathrm{a} \% 20$ evaluacion $\% 20 \mathrm{de} \%$ 20objetos\%20de\%20aprendizaje-LORI.pdf>. Acesso em: 21 maio 2012. 